\title{
Research on systemic psychology in Latin America: An integrative review with methods and data triangulation
}

\author{
Victor Rafael Rezende Celestino* \\ Julia Sursis Nobre Ferro Bucher-Maluschke \\ Universidade de Brasília, Brasilia, DF, Brasil
}

\begin{abstract}
This integrative review synthesizes convergent qualitative and quantitative data about the research on systemic psychology in Latin America, in populations without diagnosed morbidity. Eligibility criteria followed PRISMA and PICO protocols. The quality of studies was evaluated with CASP, and the synthesis method was the triangulation of methods and data. With the results from the article content analysis by means of word clouds, it was possible to contrast keywords with emerging categories and to develop a meta-synthesis, including a meta-model of the research on systemic psychology. The search was restricted to Pepsic and Web of Science databases, with a narrow focus on the theme. As the theme is inherently interdisciplinary, potential relevant studies might not have been included.
\end{abstract}

Keywords: systemic psychology, triangulation, structural meta-model, integrative review.

\section{Fazendo pesquisa em psicologia sistêmica na América Latina: Uma revisão integrativa com triangulação de métodos e dados}

\begin{abstract}
RESUMO - Esta revisão integrativa sintetiza dados qualitativos e quantitativos convergentes sobre a pesquisa em psicologia sistêmica na América Latina, em populações sem morbidade diagnosticada. Os critérios de eligibilidade seguiram os protocolos PRISMA e PICO. A qualidade dos estudos foi avaliada com o CASP, e o método de síntese foi a triangulação de métodos e dados. Como resultados, a partir da análise de conteúdo dos artigos por meio da nuvem de palavras, foi possível contrastar palavras-chave com categorias emergentes e desenvolver uma meta-síntese, incluindo um meta-modelo da pesquisa em psicologia sistêmica. A busca restringiu-se às bases Pepsic e Web of Science, com foco estreito no tema. Como o tema é inerentemente interdisciplinar, estudos potencialmente relevantes podem não ter sido incluídos.
\end{abstract}

Palavras-chave: psicologia sistêmica, triangulação, meta-modelo estrutural, revisão integrativa.

The systemic approach in psychology, called systemic psychology, has its roots in family therapy. Unlike other approaches, systemic was introduced in psychology, in the 1950 , mainly by professionals dissatisfied with results from clinical practice, and only later was it systematized by the Academia (Celestino \& Bucher-Maluschke, 2015).

Developed mainly based on general systems theory (Von Bertalanffy, 1967, 1968, 1972) and inspired by cybernetic theory (Wiener, 1948), systemic psychology has deep interdisciplinary roots. The origins of systemic thinking and the associated systemic epistemologies have been revised and reported in Latin America literature (Costa, 2010; Gomes, Bolze, Bueno, \& Crepaldi, 2014; Melo \& Ribeiro, 2016; Tinajero \& Páramo, 2012). Systemic thinking is considered an epistemological paradigm (Vasconcellos, 2003, 2004).

In relation to systemic psychology, it can be assumed that there was a decisive breakthrough of this approach in abandoning the vision of the mind as an object, and understanding it as a process (Capra \& Luigi, 2014). This new concept of mental process (Bateson, 1972) evolved into a systemic perspective, which has been incorporated

* Endereço para correspondência: $\mathrm{ADM} / \mathrm{ACE} / \mathrm{UnB}$.

Campus Darcy Ribeiro - Brasília - DF CEP 70910-900

E-mail: vrcelestino@unb.br in contemporaneous theories of cognition (H. R. Maturana \& Varela, 1980, 2001; Varela, Maturana, \& Uribe, 1974).

From then on, not only the behavior of biological systems, but also of the social systems of living beings ceases to be limited to a cybernetic self-regulation, and is associated with the autopoiesis (Cadenas \& Arnold, 2015; H. Maturana, 2015). The autopoiesis (self-generation and self-organization of living networks) is expressed in continuous processes of structural changes in response to the environment, with adaptation and learning, but with the preservation of a standard organization (Capra \& Luigi, 2014).

In systemic psychology, the focus is on communication and, therefore, on language. Despite its fuzzy origins, in practice, systemic psychology also received a strong influence of social post-structuralism. During the second half of the twentieth century, social theory achieved success in the integration of social structure and human action (agency), through the analysis and interpretation of meanings (Giddens, 1976, 1977).

Thus, in post-modernity, reflective character prevails in the choices between convictions inherited from the past and new social forms (Luvizotto, 2013). On the one hand, in a "duality of structures" (Giddens, 1976, 1977), thought and language are limited by social structures, which provide interaction and are reproduced for these interactions. At the 
same time, agency is not in discrete acts, but in a continuous stream of conduct (Capra \& Luigi, 2014).

Therefore, in an extended systemic approach to social theory, meanings represent reflective expressions. Full understanding of social phenomena, through systemic theory, requires the integration of four elements: processes, language, structures, and meanings. Society is conceived as a macro-system of network-interconnected social systems, which are based on a dialectic between social structures and human actors (Fuchs \& Hofkirchner, 2009). The structure of a social system consists of everyday social behaviors and relationships that are continuously reproduced.

In addition to being emergent, this approach is dialectical because it conceives social systems as an interconnection of human actors and social structures, and this dialectic of structures is expressed in the habitus (Bourdieu, 1967). The habitus manifests itself in macro-micro connections between social structure and agency (Vaughan, 2002). In general, similarities in the structure and in the decisionmaking patterns in natural setting are observed in relation to: complexity (interconnected layers of structure, culture, and cognition); institutional processes (persistence and variation); and habitus (dispositions system, acquired through experience).

In this extended systemic approach of social theory, the main way to transfer knowledge from one discipline to another occurs through interdisciplinarity, which raises the discussion about social languages employed in specific contexts for the production of knowledge. These "social languages" are forms of speech organization from different areas of knowledge, which are associated with different segments of civil society and academics. Each language is associated with the typical discourse of these social segments, that is, the relatively stable types of statements, which direct the permanence of the discourse at a given location and historical time. It is important to understand that these languages are organizing the production of interdisciplinary knowledge (Spink, Reigota, \& Martins, 2014).

At the global research level, a confluence of ideas and similarities between systemic thinking and critical realism (Bhaskar, 2008) is observed. Systemic thinking and its concepts are at the heart of critical realism, at the same time that critical realism can provide a philosophical base for systemic thinking (Mingers, 2014). Critical realism incorporates the understanding of multiple causal trends, interacting from genetics to discourse, in an interdisciplinary and integrative approach to science. Thus, a bridge is built between structuralism and post-structuralism in critical realism, potentializing systemic psychology to become an unified field (Pocock, 2015).

From systemic psychology perspective, the implementation of formal thinking (even reflexive) and of dialogical methods is not sufficient for two critical tasks, which are, to understand the larger whole and to appreciate other points of view. Theory and techniques need to go beyond and to access other ways of knowledge, reached by experimental, practical, or symbolic means. Therefore, systemic thinking and intervention are necessary to allow the incorporation of marginalized people and things affected by an intervention, but which do not have a voice, such as ecosystems and future generations (Rajagopalan \& Midgley, 2015).

In family therapy and systemic psychology, as the volume of literature grows, the challenges to determine what is already known and what is still not known about family and health only increase. Different studies address similar topics, but often from distinct conceptual perspectives, using different measures of the same variables and obtaining conflicting results. In this context, it is much easier to assess critically the results of a single study than to reach conclusions based on findings from multiple studies. Despite this, the practice of systemic psychology based on evidence depends upon research synthesis, performed based on explicit, valid, and reliable methods (Knafl, 2015).

Starting from the hypothesis that systemic psychology research occurs in this interdisciplinary context. Thus the question: how does systemic psychology in Latin America fit into the larger context of scientific psychology? The aim of this study is an integrative review with methods and data triangulation, to synthesize and discuss the knowledge available in the scientific literature about systemic psychology research in Latin America, in populations without diagnosed morbidity.

In particular, it is intended to contribute in two literature gaps: 1) the need to discuss if systemic psychology in Latin America is similar or not to global research; and 2) the opportunity to develop methodologies to integrate different research methods in psychology. For the research integrative synthesis, it is here explored the triangulation of methods and data. Only triangulation provides a systemic view of the phenomenon, in which "the whole is larger than the sum of the parts", amplifying validity of findings and allowing the evaluation of its convergence, complementarity, or dissonance (Tonkin-Crine et al., 2016).

This article is divided into five sections: first this introduction provides a summary of knowledge in psychology and the context of the research; the second section presents the methodology employed, especially the triangulation technique as a tool for knowledge generation; third is the results; followed by a discussion of the literature in the fourth section; and the final considerations are in the fifth and final section.

\section{Methods}

The survey was of documentary type, conducted in Brasilia, DF, Brazil, in January 2016. The Electronic journals in psychology (Pepsic) and the Web of Science (WoS) databases were consulted. The rationale for the choice of those databases is their relevance to the study. Pepsic is an open source for visibility of psychological and scientific knowledge generated in the countries of Latin America. On the other hand, the WoS database has international coverage and includes the database of the Scientific Electronic Library Online (Scielo), which is also an open source of Latin American psychological knowledge and scientific references.

This study is an integrative review, in which analyses extrapolating the synthesis of primary results are performed, encompassing other research dimensions, with the potentiality 
to develop new theories and research problems (Soares et al., 2014). Findings from qualitative, quantitative, and mixed studies are integrated in the convergent research synthesis.

For the review work, PRISMA (preferred reporting items for systematic reviews and meta-analyses) protocol was adopted. PRISMA consists of a checklist with 27 items and a flow diagram in four phases (Liberati et al., 2009). When applying PRISMA, the PICO (population, intervention, comparison, and outcome) standard was used.

Thus, the methodology of this study involves a narrow focus in the following research question: how does the term sistemica, associated with the target population, occur in scientific articles, in the selected databases? Data extraction consisted of a comprehensive search, without duplication of data in the selection of studies. The two data sources already mentioned were used. In the WoS database, only publications within the social sciences, in the areas of research in psychology and/or family studies, were considered.

The inclusion criteria was only scientific articles (quantitative, qualitative, and/or mixed studies), containing the term sistemica in the title, abstract, or keywords, published between 2014-2015, in the selected databases, in Portuguese, Spanish, or English languages.

As exclusion criteria, based on PICO, from the analysis of titles, abstracts, and keywords, studies with populations that have diagnosed morbidity (physiological or psychosomatic pathologies) were excluded. This exclusion is justified because this study is part of research applied to work and organizational environments. Other exclusion criteria were: studies that focused on hospital and/or in-patient environments (patient or caregiver populations); studies of other areas of knowledge not directly related to systemic psychology; and articles in languages other than those cited. Editorials, cases reports, theses, dissertations, and book chapters were not considered.

In this research, the quality of the work included was insured to avoid the risk of bias by individual studies, using four filters: 1) articles already screened by editorial filter; 2) articles published within the last five years; 3) critical evaluation of the included sources by CASP - Critical Appraisal Skills Programme (www.casp-uk.net); and 4) methods and data triangulation.

After the search and selection of articles, based on the defined inclusion and exclusion criteria, the articles were read in their entirety, with the goal of codification. Through the individualized assessment of each article based on CASP checklists, it was possible to determine new exclusions, which did not score sufficiently in the judges' opinion.

All the search, selection, and coding procedures of the scientific articles were conducted by two independent judges, in this case the two authors, with repetition of the process at least twice. The first author evaluated exhaustively all the selected items and coded them by filling out a digital spreadsheet from the defined criteria (Table 1). Then, the second author repeated the process by sampling. At the end, agreement and consensus on the findings were sought.

Table 1

Studies codification criteria definition

\begin{tabular}{ll}
\hline Criteria & \multicolumn{1}{c}{ Definition } \\
\hline Authors, year, and journal & Name(s) of author(s) of article, year, and publication journal. \\
Keywords & Research descriptors. \\
Title and Objective & Title and general objective of the article. \\
Design & Study design used. \\
Population (P) & Study population, with brief biodemographic description. \\
Intervention/Effect (I) & Instruments utilized. \\
Control (C) & Control groups included. \\
Outcome (O) & Brief description of main results. \\
Critical appraisal & Study quality evaluation based on CASP. \\
\hline Emerging Categories & Word cloud, with 10 (ten) most frequent terms. \\
\hline
\end{tabular}

Adopting the "best fit" search approach (Carroll, Booth, Leaviss, \& Rick, 2013), a method and data triangulation was performed for the qualitative synthesis in this integrative review. The proposed triangulation technique (Flick, 1992, 2014) aims to search, identify, select, evaluate, and summarize data from scientific articles by pre-defined criteria and emergent categories. The innovation of the proposed procedure is the identification of emergent categories, by means of the comparison among theoretical constructs, keywords declared by the authors, and the most frequent words identified in the articles analyzed (obtained through word clouds).

This triangulation allowed an integrated analysis of articles with different designs (qualitative, quantitative, and mixed). Unlike a traditional script for a systematic review, a qualitative method of content analysis is primarily employed (Flick, 2014), to construct a meta-synthesis of the findings. In addition, the study seeks to map a meta-model to understand the relationships among the key concepts of systemic psychology. 
The content analysis (Bazeley \& Jackson, 2013; Flick, 2014) was carried out with support of computational tool NVIVO 11. In the generation of word clouds, each of the sources was selected individually, from which the 10 most frequent words were searched, with at least four letters, considering radical coincidences. In addition, some common words were excluded as prohibited and not accounted for, such as pronouns, adverbs, numerals, and the name of the authors, except when these were deemed especially relevant.

With the triangulation and content analysis previously described, the categories for coding of articles were obtained. Initially, an open coding methodology (Flick, 2014) was employed, quantifying coded sources by categories. This phase was initiated with a coding from the text search of the categories, obtaining quantification by word and by source. In sequence, it was necessary to revise this coding in each selected source (article), in order to clean erroneous or repeated coding (e.g., reference titles, journal names, glossary), as well as to add coding of words or parts of text not captured by the semi-automatic coding (search by categories).

After identifying an expressive number of categories with open coding (data saturation), the next step was to refine and develop the relationship between the categories through axial coding (Flick, 2014). And the final step was selective coding, by means of which the researcher draws up or formulates a "history of her/his data" (Flick, 2014), with the establishment of a mental map expressed in a meta-model, described from the categories which it is composed of. Lastly, the categories could be semantically and/or semiotically analyzed for synonyms, metaphors, and/or metonymies.

\section{Results}

Each of the studies identified in the search conducted had its title and abstract read for the selection of those that should be included in this integrative review. This reading resulted in 17 preselected articles, which were read in full, resulting in the exclusion of nine of them that were judged of insufficient quality based on CASP. Among the 8 (eight) selected studies, Latin American researchers did not publish two of them; however, they include a Spanish language abstract containing the term "sistemica". Thus, it was decided to keep all of the studies, also for the purpose of contrasting the findings. The details about included and excluded studies based on PRISMA are presented at the appendix.

The results found no prevalent study design, with four quantitative, three qualitative, and one mixed study. The structural equation model stands out among the quantitative methods, and intervention research and case studies among the qualitative. It is worth mentioning that only one of the quantitative studies was characterized as longitudinal, with a follow-up about three to five months after the intervention, with results maintained.

The participants encompassed a wide diversity in terms of age, sex, and gender. Sample size also varied immensely, from qualitative studies with less than ten participants or a few families, to quantitative studies with 701 participants, or up to 2,500 families. The instruments employed included more than a dozen different psychometric scales. The outcome variables of the studies (primary result or dependent variable) were primarily a measure of therapy effectiveness, and some measures of constructs.

The results of the open coding with NVIVO tool are presented at figure 1 . From the 22 categories present in the coding, four of them were suppressed before the continuation of the process ("work", because of its excessive generality and scope of meanings, and the three other categories which were coded in only one article).

The main themes relevant to the analysis of the results of the selected articles deal with the 18 concepts retained. The articles included were coded in relation to the $18 \mathrm{key}-$ concepts, and the words and articles were quantified by key concept. Next, the relationship among categories was identified. Figure 2 presents the final result of the coding according to the five quadrants (phenomenon, causes, context, strategies, and consequences), after the incorporation of the structure-process-language-meanings model, and the contextualization of the main processes: habitus (selfregulation) and autopoiesis (self-organization).

Once the mental map of the meta-model (Figure 2) was established, the description of the key concepts of which it is composed of was conducted, as well as its attributes, based on semantic analysis. The coded categories were semantically analyzed and classified based on Portuguese language dictionaries (Azevedo, 2010; Ferreira, 1988). In the following text, the attributes are included in parentheses, after mentioning the related key concept.

The proposed meta-model includes a hypothesis of causality of factors (cause, parts, or components) in relation to the phenomenon. The phenomenon is modeled and described by means of: a) a structure, its organization, and agency (shape and arrangement, regularity and continuity, power in action); b) adjustment processes (conformity, accordance, self-regulation, habitus) and change (movement, replacement, variety, volitional action, tergiversation, volitional design, self-organization, autopoiesis); and c) the language of the context, including the family (ancestry and posterity, collective class, inbreeding), the community (identity), network support (assistance and cooperation, obedience, correspondence, difficulty), control (restfulness, power, restriction), and intervention (interjection, insertion, mediation).

The interaction of these components have different meanings and consequences, which can be observed indirectly from the measured behavior, through several scales, with different outcome variables (effect), and/or inventories (volition with reference to society, manifested in possession or property). Only six of the emerging key concepts of this review are not explicit in the metamodel: institutional sheltering, trust of employees, drugs, psychological empowerment, sexual orientation, and outreach. All can be considered examples of phenomena typically modeled by means of systemic psychology, for which the model can be applied. 


\begin{tabular}{|c|c|c|}
\hline Name & Sources & Referen... $v$ \\
\hline$\triangleright$ Family & 6 & 577 \\
\hline Scales factor & 6 & 415 \\
\hline Systemic clinical outcom... & 8 & 330 \\
\hline Psychotherapeutic interv... & 7 & 291 \\
\hline Community agents & 5 & 250 \\
\hline$\triangleright$ Structural and factorial $\mathrm{m} . .$. & 8 & 197 \\
\hline$>$ Work & 7 & 172 \\
\hline$\triangleright$ Employees trust & 6 & 159 \\
\hline Systemic therapy invento... & 4 & 158 \\
\hline Family change & 8 & 133 \\
\hline$\triangleright$ Organization & 5 & 130 \\
\hline$\triangleright$ Support network & 6 & 120 \\
\hline$\triangleright$ Sexual orientation & 4 & 117 \\
\hline D Psychological empowern... & 1 & 99 \\
\hline$\triangleright$ Drugs & 3 & 73 \\
\hline$\triangleright$ Outreach & 1 & 64 \\
\hline Institutional shelter & 1 & 38 \\
\hline - Socialpolitical control & 4 & 36 \\
\hline$\triangleright$ Family adjustment & 2 & 34 \\
\hline$>$ Intrapersonal & 1 & 27 \\
\hline Social participation & 1 & 24 \\
\hline$\triangleright$ Homosexuality & 1 & 15 \\
\hline
\end{tabular}

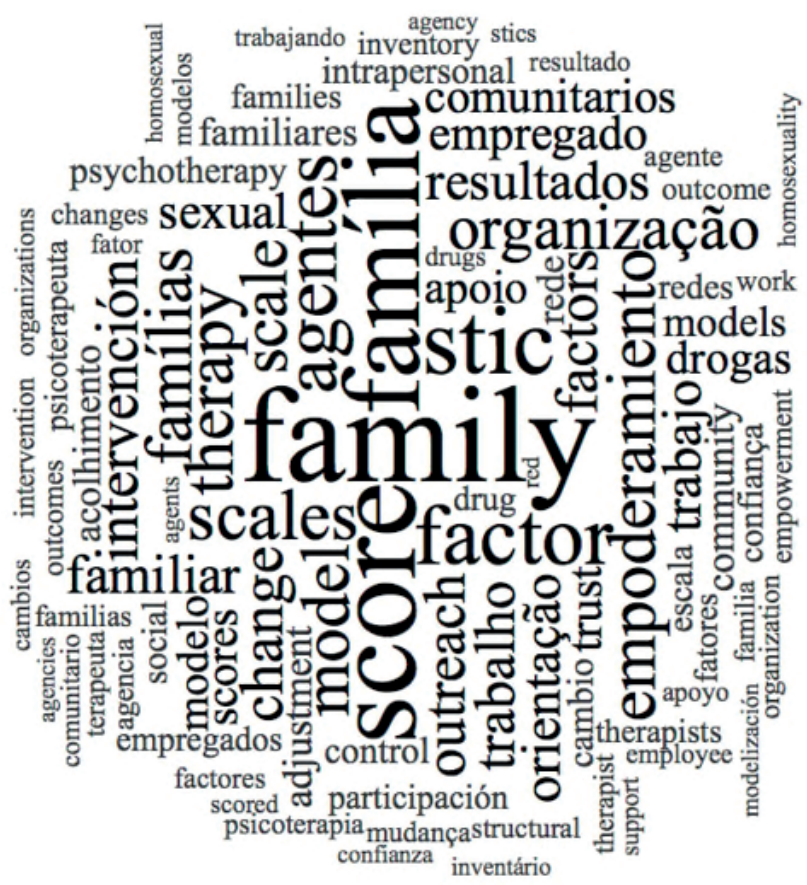

Figure 1. Results of open coding (categories and word cloud)

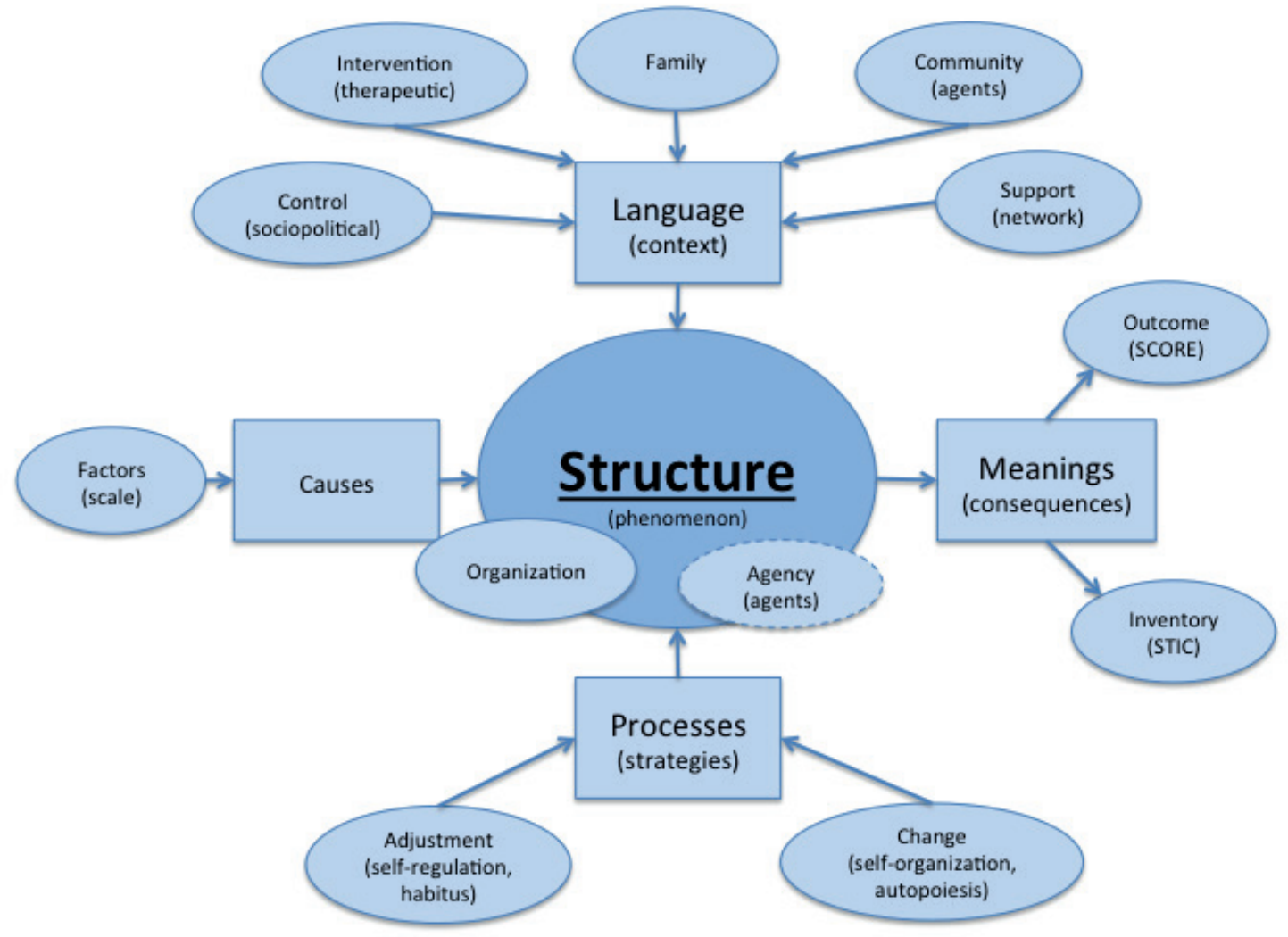

Figure 2. Meta-model of systemic psychology 


\section{Discussion}

From an evaluation of the methodological quality of systematic reviews published by Brazilian psychology journals, based on the instrument AMSTAR - Assessment of Multiple Systematic Reviews (http://amstar.ca/), no improvement was noted in the 2001-2012 period. This finding reinforce a need for standardization and adoption of guidelines by journals and authors aiming to enhance the quality of systematic reviews in Brazil (Zoltowski, Costa, Teixeira, \& Koller, 2014).

Despite the reasonable consensus that knowledge synthesis is a critical factor for practice, research, and policy improvement, it is still a challenging process to synthetize knowledge from a set of frequently heterogeneous studies. Thus, it is necessary to decide adequately which type of systematic review to conduct, considering that the most recent improvements and guidelines (protocols) to build knowledge synthesis and to report findings continuously enhance quality, scope, and applicability of the results (Whittemore, Chao, Jang, Minges, \& Park, 2014).

Certainly, a relevant aspect for the quality of knowledge synthesis is the role of critical appraisal of studies to be included in systematic reviews, though it is still questioned whether a critical appraisal can or should be used to exclude studies. However, it was already observed that the exclusion of studies considered inadequate does not affect the results in systematic reviews and that there is a correlation between the assessed quality of a study and its importance for the final synthesis (Carroll, Booth, \& Lloyd-Jones, 2012).

Generally, the exclusion of studies with inadequate quality is recommended, which was performed here based on CASP. Moreover, the format of more recent studies favors quality assessment, so inclusion of only studies published in the last five years was considered a quality threshold.

Another relevant aspect for synthesis quality is the fact that current empirical studies combine methods in a more diverse and innovative manner. A diversity is observed in the literature about the combination or integration of techniques to collect, synthetize, and analyze data, from multiple perspectives (Small, 2011). Although the research with mixed methods is not a novelty, an important contribution of the recent movement in favor of mixed methods has been the reintroduction of the discussion about how natural it is to creatively combine theories, methodologies, and/or research data (Sandelowski, 2014).

There is still no consensus about how mixed methods should be treated in a research synthesis. The quantitative component of these studies can be included in a meta-analysis, while the qualitative component can be part of the synthesis of qualitative evidence. However, the combined result can cover new areas, including in mixed methods review, and should not be neglected in a research synthesis (Boeije, van Wesel, \& Slagt, 2014). The combination of these components (qualitative and quantitative) in the discussion of results and in the research synthesis is still rare, but there already have been suggested ways to apply the synthesis of mixed research methods, with potential strength and weakness for its implementation (Heyvaert, Maes, \& Onghena, 2013).
The idea of triangulation arose with the intent to validate the results through the combination of different methods, aiming to verify the exactness and stability of observations. Initially, triangulation was conceived as a procedure to verify a hypothesis, in function of the corroboration of results obtained from different methodologies (Flick, 1992). The recent developments in qualitative approaches have allowed the reconsideration of triangulation, not only as a comparison criterion, but also as a research alternative in psychology, with rigor, amplitude, and depth (Apostolidis, 2006).

There are many techniques for qualitative data analysis which reinforce the use of methods and data triangulation for better understanding of phenomena in psychology (Leech \& Onwuegbuzie, 2007). Methods triangulation is considered as the employment of multiple methodologies to gather and analyze data from the same phenomenon, and data triangulation as the evaluation of different populations in order to obtain multiple perspectives and validate the data (Carter, Bryant-Lukosius, DiCenso, Blythe, \& Neville, 2014). Yet a theoretical triangulation could be used to explore a mechanism which facilitate or restrict agency, as well as forces and conditions that create or maintain unbalance among those involved in a researched phenomenon (Pitre \& Kushner, 2015).

Despite its dissemination, there are still few guidelines (protocols) about the operationalization of triangulation, providing an opportunity for researchers to develop, implement, and reflect upon triangulation alternatives (Farmer, Robinson, Elliott, \& Eyles, 2006). Thus, besides discussing qualitative versus quantitative research, it is up to the researcher to decide a "theoretical-methodological approach that allows, within minimum time period, to reach a result that better contributes to the understanding of the phenomenon and to the improvement of social welfare" (Günther, 2006).

This work, by means of methods and data triangulation based on content analysis, demonstrated the viability of integrating studies with different methodological characteristics, which might not have been comparable from a quantitative standpoint. The proposed qualitative meta-synthesis allowed extraction of the main themes and proposal of a meta-model to understand better the direction of results. With results herein obtained, we can now discuss how systemic psychology in Latin America contrasts with global research. The proposed meta-model showed that it dialogs adequately with a review of research results about the efficacy of systemic psychology models between 1986-95 (Sandberg et al., 1997). This review related specific modalities in certain treatments of disorders and updated a graphical meta-model of systemic psychology originally proposed (Gurman, Kniskern, \& Pinsof, 1986), with implications for clinical practice and research.

Besides, the proposed meta-model is aligned with the search of systemic psychology for the best possible treatment for each individual, from a certain therapy which presents results and is efficient in terms of cost-benefit (Singh, 2014). For this, multiple data sources and research methods, mainly qualitative, should be applied to generate a therapy rich specification and to assure that the prescribed practices 
are consistent with the systemic approach (Pote, Stratton, Cottrell, Shapiro, \& Boston, 2003).

In contrast with criteria that only identify treatments "that work", the guidelines (protocols) in systemic psychology should be classified in an evidence-based model in three levels: "informed by evidence"; "based on evidence"; and "based on evidence and ready for disclosure and intervention in different settings and communities". Each level reflects an interaction among intervention specificity, results intensity and consistency, and the quality of studies that constitute the evidence (Sexton et al., 2011).

Obviously, the results of this study, including the metamodel herein proposed, still lack these recommended proofs by evidence-based psychology. Its main value is in the proposition of a reference for comparison in this research and in future studies. Thus, findings can be contrasted and discussed in light of global research.

In this sense, a recent work examined the repercussions of several transformations and new forms in the production of scientific knowledge in Latin American psychology (Gallegos, Berra, Benito, \& López López, 2014), through a retrospective analysis of the evolution of psychology in Latin America. The researched concluded that, neither the psychology in Latin America failed to connect with the issues defined at international level, nor all themes had the same development in the region. At the same time, the progressive professionalization of psychology in Latin America cannot be seen as a mere extension of academic development, because different social demands have modeled the performance profile (Gallegos et al., 2014).

Another recent study also examined the scientific literature in psychology, based on bibliometric indicators for the period 2003-2008 (García-Martínez, Guerrero-Bote, \& Moya-Anegón, 2012). The analysis was performed by country, by research institution, and scientific journal, using the Scopus database from Elsevier. This study identified the 40 most productive countries with publications in the field of psychology (García-Martínez et al., 2012), which produced more than $98 \%$ of all production in psychology during the period. These 40 countries were divided into four groups according to production, thematic specialization, normalized citation, and percentage variation of bibliometric indicators. The study found that Brazil and Colombia were among the fastest growing countries in the production, despite not being at the top of the production, and were in the group with the largest number of countries, accounting for $10.37 \%$ of all production in psychology for 2003-2008, and $5.83 \%$ of the total number of citations (García-Martínez et al., 2012).

Finally, a study of knowledge paths between scientific disciplines is highlighted, based on data from the Web of Science, about citations between categories of subjects (Yan, 2014). The study concluded that the knowledge flow is easier from social sciences to sciences (life and biomedicine, physics, and technology) than in the opposite direction, which is attributed to the fact that the majority of the social sciences are more independent and primarily cite their own publications. Even among social sciences disciplines, the path is longer because they are more self-contained and less unified in comparison with the other science disciplines. From this, it follows obviously that the flow of knowledge from and to the social sciences is less fluid than among sciences disciplines, which access other domains more easily (Yan, 2014).

Moreover, the study identified that the majority (60\%) of the paths between two disciplines of social sciences go through another intermediate discipline, that is, only the minority of paths have direct interdisciplinary exchanges (Yan, 2014). Figure 3 shows a map of knowledge flows between disciplines of the social sciences in the Web of Science. The backbone of the social sciences is evident. The flow of knowledge from other disciplines of social sciences is facilitated by this backbone of knowledge paths (Yan, 2014), where systemic psychology can be identified associated with family studies.

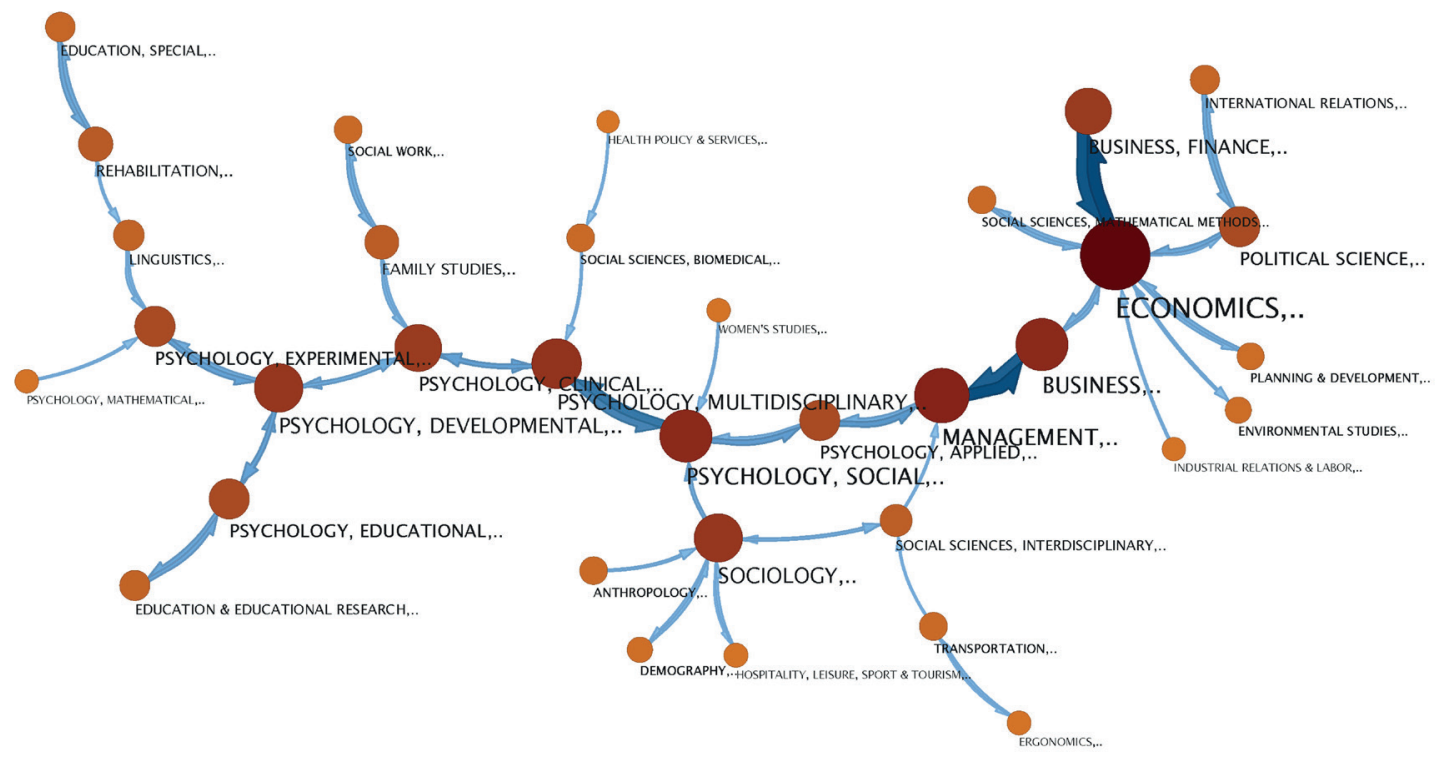

Figure 3. Backbone of the knowledge flow in social sciences

Source: Yan, E. (2014). Finding knowledge paths among scientific disciplines. Journal of the Association for Information Science and Technology, 65(11), 2331-2347. doi:10.1002/asi.23106. Rights reserved to John Wiley \& Sons. Reprinted with permission 
In short, this study was grounded in the interdisciplinarity of systemic perspective and sought a transdisciplinary synthesis. The resulting 18 key-concepts harmonically dialogue with the themes of global research, with some specificity of the phenomena, but are also well aligned with issues of clinical psychology and social work, in tune with the overall trend of the family studies (figure 3 ). The analysis of the 18 key-concepts, individually and together, allows a metasynthesis of the systemic approach of psychology, including through a proposal of a meta-model for the understanding of this scientific approach.

As stated in the introduction, systemic psychology models and studies the phenomena through structures, which are subject to processes of autopoiesis (self-organization) and habitus (self-regulation), to take account of interactions with the environment by means of language, conveying meanings expressed in an observable behavior. All these aspects were captured in the proposed model, which was described previously.

Finally, the potential limitations and bias of this study must be considered. First, the research focus was purposely narrow, which might have introduced a bias in relation to systemic thinking, which has a larger scope. Moreover, the search was restricted to two databases, focusing in the areas of psychology and family studies. As the topic is inherently interdisciplinary, not all the production on systemic theory is in the field of psychology and in journals exclusive to the area. Therefore, potentially relevant studies may not have been included in the sample evaluated.

There is no potential conflict of interest in relation to the research and the findings.

\section{Final Considerations}

This work presents a methods and data triangulation proposal to synthesize and discuss the available knowledge in the scientific literature about systemic psychology research in Latin America. The possibility of constructing and proposing a meta-model from the findings facilitates possible initiatives for its replication, which sets a benchmark for future comparisons. In addition, this meta-model can serve future objectives to analyze phenomena with different methodologies, in the light of the systemic psychology approach.

\section{References}

Apostolidis, T. (2006). Representations sociales et triangulation: Une application en psychologie sociale de la sante. [Social representation and triangulation: An application in health social psychology]. Psicologia: Teoria e Pesquisa, 22, 211-226.

Azevedo, F. F. d. S. (Ed.). (2010) Dicionário analógico da língua portuguesa: Ideias afins / thesaurus [Portuguese language analogic dictionary: related ideas / thesaurus] (2 ed.). Rio de Janeiro: Lexikon.

Bateson, G. (1972). Steps to an ecology of mind: Collected essays in anthropology, psychiatry, evolution, and epistemology. Chicago: University of Chicago Press.
Bazeley, P., \& Jackson, K. (2013). Qualitative data analysis with NVivo. London: Sage Publications Limited.

Bhaskar, R. (2008). A realist theory of science. Abingdon: Routledge.

Boeije, H., van Wesel, F., \& Slagt, M. (2014). Guidance for deciding upon use of primary mixed methods studies in research synthesis: lessons learned in childhood trauma. Quality \& Quantity, 48(2), 1075-1088. doi:10.1007/s11135-012-9825-x

Bourdieu, P. (1967). Estrutura, habitus e prática [Structure, habitus and practice]. In P. Bourdieu (Ed.), A economia das trocas simbólicas [The economy of symbolic exchanges] (pp. 203229). São Paulo: Perspectiva.

Cadenas, H., \& Arnold, M. (2015). The autopoiesis of social systems and its criticisms. Constructivist Foundations, 10(2), 169-176.

Capra, F., \& Luigi, P. (2014). A visão sistêmica da vida. Uma concepção unificada e suas implicações filosóficas, políticas, sociais e econômicas [Life systemic view. An unified concept and its philosophical implications]. São Paulo: Cultrix.

Carroll, C., Booth, A., Leaviss, J., \& Rick, J. (2013). "Best fit" framework synthesis: Refining the method. Bmc Medical Research Methodology, 13, 16. doi:10.1186/1471-2288-13-37

Carroll, C., Booth, A., \& Lloyd-Jones, M. (2012). Should we exclude inadequately reported studies from qualitative systematic reviews? An evaluation of sensitivity analyses in two case study reviews. Qualitative Health Research, 22(10), 1425-1434. doi:10.1177/1049732312452937

Carter, N., Bryant-Lukosius, D., DiCenso, A., Blythe, J., \& Neville, A. J. (2014). The use of triangulation in qualitative research. Oncology Nursing Forum, 41(5), 545-547. doi:10.1188/14. ONF.545-547

Celestino, V. R. R., \& Bucher-Maluschke, J. S. N. F. (2015). Um novo olhar para a abordagem sistêmica na psicologia. [A new look to the systemic approach in psychology]. FACEF Pesquisa - Desenvolvimento e Gestão, 18(3), 318-329.

Costa, L. F. (2010). A perspectiva sistêmica para a Clínica da Família. [The systemic perspective for family clinics]. Psicologia: Teoria e Pesquisa, 26, 95-104.

Farmer, T., Robinson, K., Elliott, S. J., \& Eyles, J. (2006). Developing and implementing a triangulation protocol for qualitative health research. Qualitative Health Research, 16(3), 377-394. doi:10.1177/1049732305285708

Ferreira, A. B. d. H. (Ed.). (1988) Dicionário Aurélio Básico da Língua Portuguesa [Portuguese language basic Aurelio dictionary]. Rio de Janeiro: Nova Fronteira.

Flick, U. (1992). Triangulation revisited: Strategy of validation or alternative. Journal for the Theory of Social Behaviour, 22(2), 175-197. doi:10.1111/j.1468-5914.1992.tb00215.x

Flick, U. (2014). An introduction to qualitative research (5 ed.). Los Angeles: SAGE.

Fuchs, C., \& Hofkirchner, W. (2009). Autopoiesis and critical social systems theory. In R. Magalhaes \& R. Sanchez (Eds.), Autopoiesis in organization theory and practice(pp. 111-129).

Gallegos, M., Berra, M., Benito, E., \& López López, W. (2014). Las nuevas dinámicas del conocimiento científico y su impacto en la psicología latinoamericana. [The new scientific knowledge dynamics and its impact on psychology in Latin America]. Psicoperspectivas, 13(3), 106-117. doi:10.5027/ psicoperspectivas-Vol13-Issue3-fulltext-377 
García-Martínez, A. T., Guerrero-Bote, V. P., \& Moya-Anegón, F. d. (2012). World scientific production in Psychology. Universitas Psychologica, 11(3), 699-717.

Giddens, A. (1976). Classical social theory and origins of modern sociology. American Journal of Sociology, 81(4), 703-729. doi:10.1086/226140

Giddens, A. (1977). Habermas's social and political theory: toward a rational society. American Journal of Sociology, 83(1), 198212. doi:10.1086/226517

Gomes, L. B., Bolze, S. D. A., Bueno, R. K., \& Crepaldi, M. A. (2014). As origens do pensamento sistêmico: Das partes para o todo. [The origins of systemic thinking: from the parts to the whole]. Pensando familias, 18(2), 3-16.

Günther, H. (2006). Pesquisa qualitativa versus pesquisa quantitativa: Esta é a questão? [Qualitative research versus quantitative research: this is the question?]. Psicologia: Teoria e Pesquisa, 22, 201-209.

Gurman, A. S., Kniskern, D. P., \& Pinsof, W. M. (1986). Research on the process and outcome of marital and family therapy. Handbook of psychotherapy and behavior change, 3, 565-624.

Heyvaert, M., Maes, B., \& Onghena, P. (2013). Mixed methods research synthesis: Definition, framework, and potential. Quality \& Quantity, 47(2), 659-676. doi:10.1007/s11135011-9538-6

Knafl, K. (2015). Family synthesis research: Possibilities and challenges. Journal of Family Nursing, 21(1), 3-10. doi:10.1177/1074840714568740

Leech, N. L., \& Onwuegbuzie, A. J. (2007). An array of qualitative data analysis tools: A call for data analysis triangulation. School Psychology Quarterly, 22(4), 557-584. doi:10.1037/10453830.22.4.557

Liberati, A., Altman, D. G., Tetzlaff, J., Mulrow, C., Gotzsche, P. C., Ioannidis, J. P. A., . . Moher, D. (2009). The PRISMA statement for reporting systematic reviews and meta-analyses of studies that evaluate health care interventions: explanation and elaboration. Annals of Internal Medicine, 151(4), W65-W94.

Luvizotto, C. K. (2013). The rationalization of traditions in modernity: The dialogue between Anthony Giddens and Jurgen Habermas. Trans-Form-Acao, 36, 245-258.

Maturana, H. (2015). What Is Sociology? Constructivist Foundations, 10(2), 176-179.

Maturana, H. R., \& Varela, F. J. (1980). Autopoiesis and cognition: The realization of the living. Dordrecht: $\mathrm{D}$. Reidel.

Maturana, H. R., \& Varela, F. J. (2001). A árvore do conhecimento: as bases biológicas da compreensão humana. [The tree of knowledge: the biological basis of human understanding.]. São Paulo: Palas Athena.

Melo, V. d. A. A., \& Ribeiro, M. A. (2016). Epistemologias sistêmicas e suas repercussões para a clínica da terapia familiar. [Systemic epistemologies and its repercussions for family therapy clinics]. Pensando familias, 20, 149-161.

Mingers, J. (2014). Systems thinking, critical realism and philosophy: A confluence of ideas. Abingdon: Routledge.

Pitre, N. Y., \& Kushner, K. E. (2015). Theoretical triangulation as an extension of feminist intersectionality in qualitative family research. Journal of Family Theory \& Review, 7(3), 284-298. doi:10.1111/jftr. 12084
Pocock, D. (2015). A philosophy of practice for systemic psychotherapy: The case for critical realism. Journal of Family Therapy, 37(2), 167-183. doi:10.1111/1467-6427.12027

Pote, H., Stratton, P., Cottrell, D., Shapiro, D., \& Boston, P. (2003). Systemic family therapy can be manualized: Research process and findings. Journal of Family Therapy, 25(3), 236-262. doi:10.1111/1467-6427.00247

Rajagopalan, R., \& Midgley, G. (2015). Knowing differently in systemic intervention. Systems Research and Behavioral Science, 32(5), 546-561. doi:10.1002/sres.2352

Sandberg, J. G., Johnson, L. N., Dermer, S. B., GfellerStrouts, L. L., Seibold, J. M., StringerSeibold, T. A., . . Miller, R. B. (1997). Demonstrated efficacy of models of marriage and family therapy: An update of Gurman, Kniskern, and Pinsof's chart. American Journal of Family Therapy, 25(2), 121-137. doi:10.1080/01926189708251061

Sandelowski, M. (2014). Unmixing mixed-methods research. Research in Nursing \& Health, 37(1), 3-8. doi:10.1002/ nur. 21570

Sexton, T., Gordon, K. C., Gurman, A., Lebow, J., HoltzworthMunroe, A., \& Johnson, S. (2011). Guidelines for Classifying Evidence-Based Treatments in Couple and Family Therapy. Family process, 50(3), 377-392.

Singh, R. (2014). Evidence-based practice and practice-based evidence: reasons for optimism. Journal of Family Therapy, 36(2), 105-106. doi:10.1111/1467-6427.12039

Small, M. L. (2011). How to conduct a mixed methods study: recent trends in a rapidly growing literature. Annual Review of Sociology, 37, 57-86. doi:10.1146/annurev.soc.012809.102657

Soares, C. B., Hoga, L. A. K., Peduzzi, M., Sangaleti, C., Yonekura, T., \& Silva, D. R. A. D. (2014). Integrative review: concepts and methods used in nursing. Revista da Escola de Enfermagem da USP, 48(2), 335-345. doi:10.1590/S00806234201400002000020

Spink, M. J. P., Reigota, M. A. d. S., \& Martins, M. H. d. M. (2014). Linguistic repertoires of interdisciplinarity in brazilian journals in the area of psychology. Repertorios lingüísticos de interdisciplinaridad en revistas brasileñas de psicología. Repertórios linguísticos de interdisciplinaridade em revistas brasileiras da área de psicologia. Paidéia, 24(59), 371-378. doi:10.1590/1982-43272459201411

Tinajero, C., \& Páramo, M. F. (2012). The systems approach in developmental psychology: fundamental concepts and principles fundamentais. Psicologia: Teoria e Pesquisa, 28(4), 457-465. doi:10.1590/S0102-37722012000400011

Tonkin-Crine, S., Anthierens, S., Hood, K., Yardley, L., Cals, J. W., Francis, N. A., . . consortium, G. I. C. (2016). Discrepancies between qualitative and quantitative evaluation of randomised controlled trial results: achieving clarity through mixed methods triangulation. Implement Sci, 11, 66. doi:10.1186/ s13012-016-0436-0

Varela, F. J., Maturana, H. R., \& Uribe, R. B. (1974). Autopoiesis: the organization of living systems, its characterization and a model. Curr Mod Biol, 5(4), 187-196.

Vasconcellos, M. J. E. (2003). Pensando o pensamento sistêmico novo paradigmático e suas implicações. [Thinking systemic thinking new paradigm and its implications]. Eisforia, 1(2). 
Vasconcellos, M. J. E. (2004). Implicações do pensamento sistêmico novo-paradigmático: A questão da dicotomia "terapia familiar sistêmica"/"terapia familiar narrativista". [Implications of systemic thinking new paradigm: the question of the dichotomy systemic family therapy / narrative family therapy]. Nova Perspectiva Sistêmica, 12(24), 7-13.

Vaughan, D. (2002). Signals and interpretive work: The role of culture in a theory of practical action. In K. A. Cerullo (Ed.), Culture in mind: Toward a sociology of culture and cognition(pp. 28-54). New York: Routledge.

Von Bertalanffy, L. (1967). General theory of systems: Application to psychology. Information (International Social Science Council), 6(6), 125-136.

Von Bertalanffy, L. (1968). General system theory: Foundations, development, applications. New York: George Brazilier.

Von Bertalanffy, L. (1972). The history and status of general systems theory. Academy of Management Journal, 15(4), 407-426.

Whittemore, R., Chao, A., Jang, M., Minges, K. E., \& Park, C. (2014). Methods for knowledge synthesis: An overview. Heart \& Lung, 43(5), 453-461. doi:10.1016/j.hrtlng.2014.05.014

Wiener, N. (1948). Cybernetics. Scientific American, 179(5), 14-18.
Yan, E. (2014). Finding Knowledge Paths Among Scientific Disciplines. Journal of the Association for Information Science and Technology, 65(11), 2331-2347. doi:10.1002/asi.23106

Zoltowski, A. P. C., Costa, A. B., Teixeira, M. A. P., \& Koller, S. H. (2014). Qualidade metodológica das revisões sistemáticas em periódicos de psicologia brasileiros. [Methodological quality of systematic reviews in Brazilian psychology journals]. Psicologia: Teoria e Pesquisa, 30(1), 97-104. doi:10.1590/ s0102-37722014000100012
Recebido em 29/07/2016

Revisado em 03/03/2017

Aceito em 04/04/2017 
Appendix I. Graphical Synthesis of Search in Databases (PRISMA)

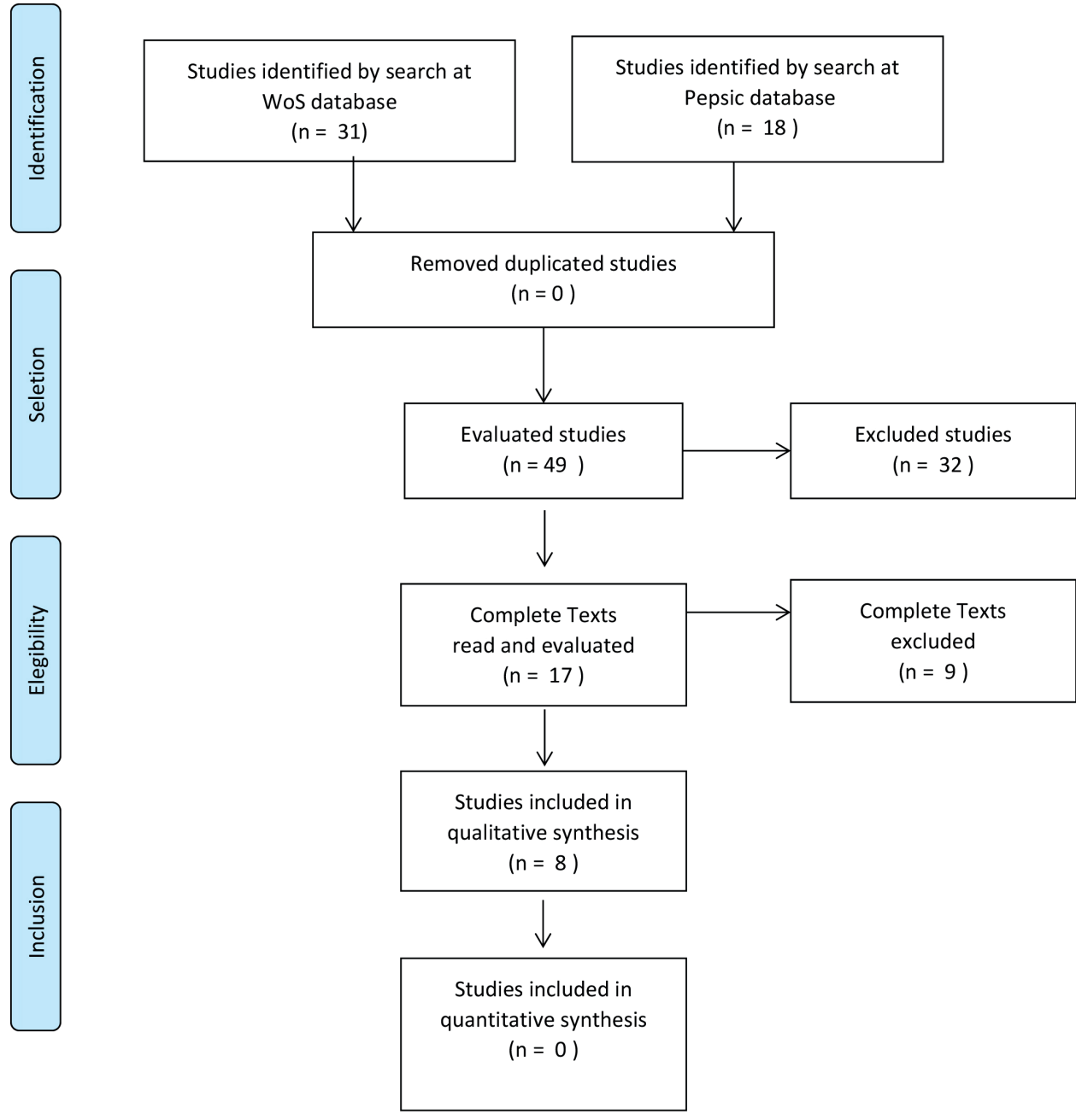

Appendix II. Results from search at Pepsic and Web of Knowledge bases (8)

Banda Castro, A. L., \& Morales Zamorano, M. A. (2015). Empoderamiento psicológico: un modelo sistémico con componentes individuales y comunitarios. [Psychological empowerment: a systemic model with individual and community components]. Revista de Psicología (PUCP), 33(1), 3-20.

Hamilton, E., Carr, A., Cahill, P., Cassells, C., \& Hartnett, D. (2015). Psychometric properties and responsiveness to change of 15-and 28-item versions of the SCORE: a family assessment questionnaire. Family process, 54(3), 454-463. doi:10.1111/ famp. 12117

Jaramillo, A., Hidalgo, C. G., Armijo, I., Hayden, V., Santis, R., \& Lasagna, A. (2014). Aspectos clave en el desempeño exitoso de agentes comunitarios en intervenciones de outreach con jóvenes consumidores de drogas. [Key aspects for successful performance of community agents in outreach interventions with young drug users]. Psykhe (Santiago), 23(1), 1-14. doi:10.7764/psykhe.23.1.666

Lima, F. T. I., Pedroso, J. d. S., \& Magalhães, C. M. C. (2014). Redes de apoio de famílias de crianças em acolhimento institucional. [Support network of families with children in institutional shelter]. Revista Mal Estar e Subjetividade, 14, 84-92.
Medina Peralta, M. (2014). Psicoterapia breve en grupo: una modalidad práctica con enfoque constructivista y ecosistémico para la solución de problemas. [Brief groups psychotherapy: a practical embodiment with constructivist and ecosystemic for troubleshooting]. Diversitas: Perspectivas en Psicología, $10(2), 247-260$.

Oliveira, Á. d. F., \& Souza, M. A. d. (2014). Confiança do empregado na organização: o impacto dos valores pessoais e organizacionais. [Employee's trust in the organization: the impact of personal and organizational values]. Revista Psicologia Organizações e Trabalho, 14, 204-217.

Pinsof, W. M., Zinbarg, R. E., Shimokawa, K., Latta, T. A., Goldsmith, J. Z., Knobloch-Fedders, L. M., . . L Lebow, J. L. (2015). Confirming, validating, and norming the factor structure of systemic therapy inventory of change initial and intersession. Family process, 54(3), 464-484. doi:10.1111/ famp. 12159

Silva, M. M. d. L., Frutuozo, J. F. F., Feijó, M. R., Valerio, N. I., \& Chaves, U. H. (2015). Família e orientação sexual: dificuldades na aceitação da homossexualidade masculina. [Family and sexual orientation: difficulties in the acceptance of male homosexuality]. Temas em Psicologia, 23, 677-692. 